\title{
In Memory of Nikolai Vladimirovich Churaev (1920-2010)
}

DOI: $10.1134 / \mathrm{S} 1061933 \mathrm{X} 10030191$

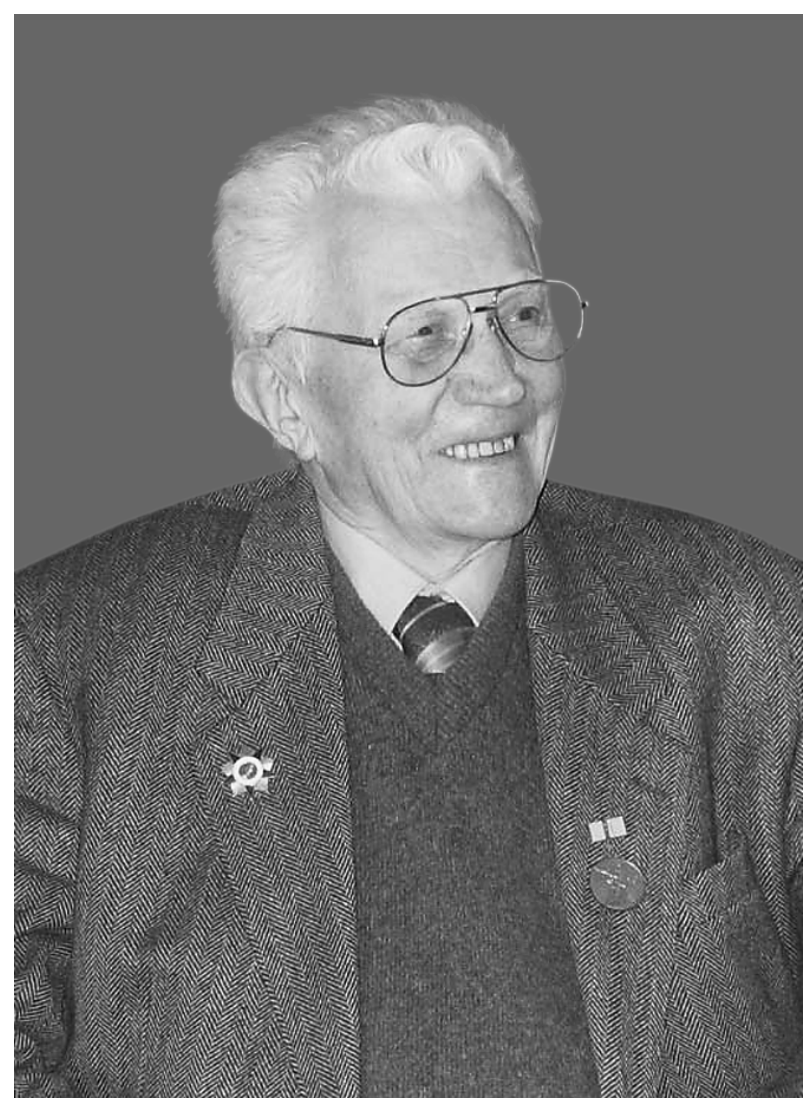

Professor Nikolai Vladimirovich Churaev, Editorin-Chief of our journal, one of the most well-known scientists in the field of colloids and surface phenomena worldwide, passed away on February 4, 2010.

During his long life of almost 90 years, Churaev managed a great deal. In 1954, he began working at the Moscow Peat Institute and for 10 years, he traversed from Assistant to Full Professor of the Chair of Physics at this institute and organized one of the first radioisotope laboratories. In the same period, he was engaged in studying the processes of evaporation and transfer of moisture within porous bodies, film flow, wetting, and capillary rise of liquids, In 1964, Churaev began his work with B.V. Derjaguin, which, in many respects, predetermined his subsequent path in science. In 1965, at Derjaguin's suggestion, he was transferred to the Institute of Physical Chemistry, USSR Academy of Sciences (nowadays the Frumkin Institute of Physical Chemistry and Electrochemistry, Russian Academy of Sciences), with which he was associated the rest of his life. From 1967 to 1989, Churaev headed the Laboratory of Thin Liquid Layers and he further worked at this laboratory as chief researcher.

The fundamental studies in the fields of surface forces, wetting films, mechanisms of membrane separation of solutions performed under his guidance were distinguished by a unique combination of sophisticated theoretical analysis of the studied phenomena and magnificent design of experiments. Their results, which were reflected in several hundred scientific papers and nine monographs, made Churaev a worldfamed scientist.

For many years, he headed Kolloidnyi Zhurnal (Colloid Journal), which, over this time, became an authoritative international scientific publication.

All of us, the Editorial Board, friends, students, and colleagues, deeply grieve the death of Nikolai Vladimirovich Churaev, an outstanding scientist, and a wise, kind person. We will cherish his memory. 